\title{
Effects of Cold-Rolling and Subsequent Heat Treatments on Structural, Mechanical and Electrical Properties of a Commercial Al Alloy
}

\author{
H.N. Soliman, A. Rizk \\ Physics Department, Faculty of Education, Ain Shams University, \\ Roxy, Cairo, Egypt.
}

Commercial Al alloys are used in a wide range of industrial applications, especially in aerospace and automotive applications, where a good corrosion resistance is required. Recently, there has been a growing interest in using cold rolling as a method to produce low-cost aluminum sheets for automotive applications. The present work was undertaken to investigate the effects of cold rolling and subsequent annealing at temperatures (373, 573 and $773 \mathrm{~K}$ ) on structural, mechanical and electrical properties of a commercial Al alloy. The results showed that (1) cold rolling of the as-received samples increased their hardness bya factor that was dependent on the degree of rolling stain; (2) annealing the rolled samples at different temperatures weakened their hardness, and (3) the electrical resistivity for Al samples increased with increasing rolling strain up to $40 \%$ then sharply decreased. These effects were explored using optical microscopy, Vickers microhardness tester and X-ray diffraction analysis.

\section{Introduction:}

The properties of aluminum make it one of the most advantageous and versatile materials in use today. While lighter weight is the primary reason for selecting aluminum for body applications, outstanding corrosion performance provides an additional advantage that is highly important in extending the life of a vehicle [1,2]. Moreover, aluminum and its alloys have an exclusive barrier properties and result to be an ideal packaging materials. In addition, they are applied as the materials for body panels of the automobile and the hydrogen gas vessels with high temperature applications [3-6]. This wide range of products demands combinations of properties such as high strength, good corrosion resistance, good formability, good machinability, high toughness, good ballistic performance etc.

Undoubtedly, some of the most widely used products in our daily life are made from rolling aluminium slabs. Rolled aluminium products can be found almost everywhere. Cookware, beverage cans and air conditioners all made from slabs. They are extensively used in packaging, transport and building industries as well as in general engineering applications [7-10]. 
Rolling aluminium and its alloys is one of the principle ways of converting cast aluminium slab from the smelters and wrought re-melts into a usable industrial form. Common to all rolled aluminium products are the properties of lightness, strength and durability. These three, coupled with other specific properties for particular applications, make rolled aluminium one of the most versatile materials available for the major markets of packaging, transport, and construction.

The use of aluminium instead of heavier alternative materials enables significant energy savings to be made over the product's life cycle, for example in transportation and in all areas where products move or are carried. Metal recovery is another important characteristic, aluminium is easily recycled after use and similar rolled products to those recycled can be produced using only $5 \%$ of the energy required to make the initial primary metal. The rolling of cast aluminium changes its metallic structure and the metal takes on new characteristics and properties. The brittleness of the coarse, as-cast structure is replaced by a stronger and more ductile material, with the degrees of strength and ductility being variable factors that are functions of the amount of rolling given to the metal, the rolling temperature, the alloy composition and the use of annealing.

Electrical resistivity is one of the most sensitive properties of commercial $\mathrm{Al}$ alloys, being particularly responsive to changes in composition and temper. On the other hand, the grain size is one of the most important microstructural factors controlling strength and formability. So, it is important to obtain an optimal grain size, and to have a good combination of strength and formability. The grain size is controlled by an appropriate combination of cold rolling and annealing [11-14].

In this paper the attention will be oriented to study the effects subsequent annealing temperatures on structural, mechanical and electrical properties of cold-rolled Al-material used.

\section{Material Used:}

In particular, the commercial 99.8at.\% Al alloy has been employed for the present research. This alloy was supplied in the form of blocks from General Metal Company Tebbin-Helwan-Cairo-Egypt and its chemical composition is presented in Table 1.

\section{Experimental Details:}

\subsection{Cold Rolling and Heat Treatment}

Samples with dimensions, $120 \mathrm{~mm}$ long, $10 \mathrm{~mm}$ wide, $10 \mathrm{~mm}$ thick, were cut from as-received blocks. Seven pieces of these samples were then cold rolled to different rolling strains $(10,20,30,40,50,60$ and $70 \%)$. Reduction per pass was maintained constant at $10 \%$. 
During the rolling stages some lubrication is needed, since otherwise the sample surface can become marked with different scratches. These lubricants are sprayed on the sample surface before passing through the rolling mill. The obtained cold rolled samples of the given alloy were annealed in groups in the temperature range (373-773 K) for $1 \mathrm{~h}$ followed by water quenching.

\subsection{Grain Size and Hardness Testing}

All samples were grounded on fine grades of silicon carbide papers then were electopolished using a solution of $25 \mathrm{ml}$ distilled $\mathrm{H}_{2} \mathrm{O}, 38 \mathrm{ml}$ ethyl alcohol and $40 \mathrm{ml} \mathrm{H}_{3} \mathrm{PO}_{4}$ acid with an aluminum cathode. To establish the right conditions for electro-polishing it was necessary to obtain the voltage-current relationship for the electrolyte and sample material used. This was done by placing a test sample as anode in the electrolyte and plotting graphically the voltage-current curve. An applied voltage of $20 \mathrm{~V}$ and corresponding current 0.8 A were found suitable for these samples and the electrolyte used at a temperature ranged from 288 to $293 \mathrm{~K}$. The samples, after electropolishing were washed thoroughly with distilled $\mathrm{H}_{2} \mathrm{O}$ and ethyl alcohol. The above polished samples were degreased using ethanol in an ultrasonic bath for $30 \mathrm{~min}$ then dried and placed in a desiccator until testing.

To reveal the grain boundaries, the electropolished samples were etched for about $8 \mathrm{~s}$ at room temperature using a mixture of $50 \%$ concentrated $\mathrm{HCl}, 47 \%$ $\mathrm{HNO}_{3}$ and $3 \%$ concentrated HF [15]. After etching, the samples were cleaned with distilled $\mathrm{H}_{2} \mathrm{O}$ and ethyl alcohol. The average grain size was determined using the standard linear intercept method.

Vickers microhardness measurements have been adopted for the estimation of the alloy mechanical behavior. Vickers microhardness tester (Model MHP 160) was used to measure the hardness of different alloy samples under the load of $0.01 \mathrm{kgf}$ for $30 \mathrm{~s}$. To achieve the best reproducibility of hardness values, at least 15 indentations at various locations for each sample were considered and an average value was calculated.

Optical microscopy with a digital camera attachment (Model MF-AKS Photomicrographic Equipment $24 \times 36$ AUTOMATIC-2) was used for the microscopic study.

\subsection{Electrical Resistivity}

Electrical resistivity measurements were performed by running a current through two copper blocks which support the sample between them. Voltage measurements were taken from a microvoltmeter to determine the potential drop across the sample (20 $\mathrm{mm}$ long). 
An 10-ohm resistor was placed in the circuit to ensure a constant current of 0.4 A. The output from a dc power supply was adjusted to provide the required current.

Table (1): The chemical composition (at.\%) of the investigated commercial Al alloy.

\begin{tabular}{|c|c|c|c|c|}
\hline $\mathrm{Si}$ & $\mathrm{Zn}$ & $\mathrm{Fe}$ & $\mathrm{Ti}$ & $\mathrm{Al}$ \\
\hline 0.140 & 0.021 & 0.020 & 0.017 & Balance \\
\hline
\end{tabular}

The average voltage drop $\boldsymbol{V}$ across a certain length of the sample $(10 \mathrm{~mm})$ was measured using dc-microvoltmeter (Philips PM 2434) and the electrical resistivity $\rho$ was obtained using the equation:

$$
\rho=\frac{V A}{I L}
$$

where $\boldsymbol{A}$ and $\boldsymbol{L}$ are the cross-sectional area and the length of the sample between the microvoltmeter electrodes.

\subsection{X-ray Diffraction Analysis}

$\mathrm{X}$-ray analysis of the above treated samples was performed using X-ray diffractometry (Nanotechnology and Advanced Material Centeral Characterization Lab.-Agricultural Research Center-Cairo University). Filtered $\mathrm{CuK} \alpha$ radiation with a wavelength of $1.5406 \AA$ 位 was used. The X-ray diffraction (XRD) patterns over a wide range of diffraction angles $2 \theta$ ranging from $20^{\circ}$ to $100^{\circ}$ were recorded at room temperature.

\section{Results and Discussion:}

\subsection{Effects of Annealing Temperature and Cold Rolling on the Grain Size and Shape of the Al Alloy}

Samples of average grain sizes $154 \pm 11,213 \pm 8$ and $256 \pm 6 \mu \mathrm{m}$ (Fig.1a-c) were obtained by annealing the samples at the different temperatures 373,573 and $773 \mathrm{~K}$, respectively.

It is interesting to notice the formation of subgrains in Fig. (1c) with an average diameter of $15 \pm 1.5 \mu \mathrm{m}$. This is due to the fact that upon progressing stages of annealing most of the dislocations of opposite sign annihilate each other and the remaining dislocations are arranged in the form of low angle grain boundaries. The newly formed cells are called subgrains [16].

Photomicrographs of $\mathrm{Al}$ samples rolled to different strains (50 and 70\%) and annealed for $1 \mathrm{~h}$ at the same temperature of $573 \mathrm{~K}$ are shown in Fig. (2a \& b). The alloy reveals deformed grain structures associated with an elongation of the grains parallel to the rolling direction. 



Fig. (1): Grain sizes of commercial Al samples annealed for $1 \mathrm{~h}$ at the temperatures: (a) $373 \mathrm{~K}(154 \pm 11 \mu \mathrm{m})$; (b) $573 \mathrm{~K}(213 \pm 8 \mu \mathrm{m})$; (c) $773 \mathrm{~K}(256 \pm 6 \mu \mathrm{m})$. (before rolling). 

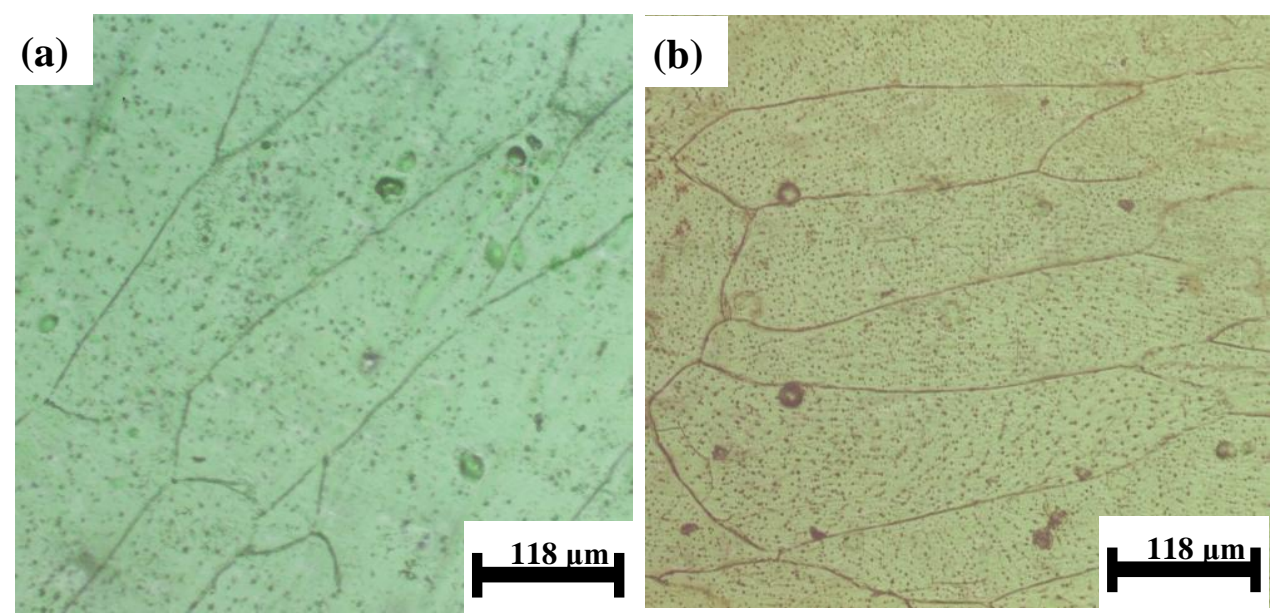

Fig. (2): Shapes of grains of samples that were annealed at $573 \mathrm{~K}$ after rolling to strains of: (a) 50\%; (b) 70\%. (compare with Fig. $1 \mathrm{~b}$ before rolling)

\subsection{Effect of Cold Rolling on Hardness Measurements of As-received and Annealed Al Samples}

The strength of materials can be enhanced by using various common techniques such as grain size refinement, strain hardening (rolling), solid solution hardening, anneal hardening, quench hardening, dispersion strengthening and precipitation hardening [17].

Figure (3) shows the variation of hardness of different Al samples with the degree of rolling strain. It was noted that the hardness of the as-received and annealed samples increase with rolling strains up to a maximum value due to strain hardening, and then slightly decrease. Maximum value of hardness (for the as-received) was about $9.6 \mathrm{HV}$ for $50 \%$ reduction i.e. maximum of work hardening was attained in the alloy. This gradual increase in $\mathrm{H}_{\mathrm{V}}$ values may be attributed to the the partial increase of crystal imperfections introduced during cold rolling process. If we assume solute segregation to dislocations, analogous to the formation of Cottrell atmosphere, as the mechanism of anneal hardening effect, the flow stress should be increased by the binding of solute atoms to dislocations. The interactions of solute atoms with lattice defects such as dislocations, vacancies and stacking faults introduced during rolling, however, may also cause a considerable increase in hardness values. Solute interactions with vacancy clusters could possibly contribute to the strengthening too $[18,19]$.

The observed drop in the hardness values of all samples rolled to a strain of $70 \%$ cannot be understood unless a recovery mechanism is considered. It is possible that part of the energy acquired by this material (when rolled at high strains) is used in the migration of the larger clusters of solute-vacancy pairs (formed at lower strains) towards dislocations [20]. This decreases the matrix free-energy and causes the observed weakened behaviour of the material. 
On the other hand, Fig. (3) also shows that $\mathrm{H}_{\mathrm{V}}$ values for the annealed $\mathrm{Al}$ samples decrease with increasing annealing temperature. This significant decrease in $\mathrm{H}_{\mathrm{V}}$ values may be attributed to the reduction of hardening effect. Furthermore, one can predicts that the recrystallization rate of the given alloy was increased at higher annealing temperatures and consequently a sharp decrease in $\mathrm{H}_{\mathrm{V}}$ values were observed.

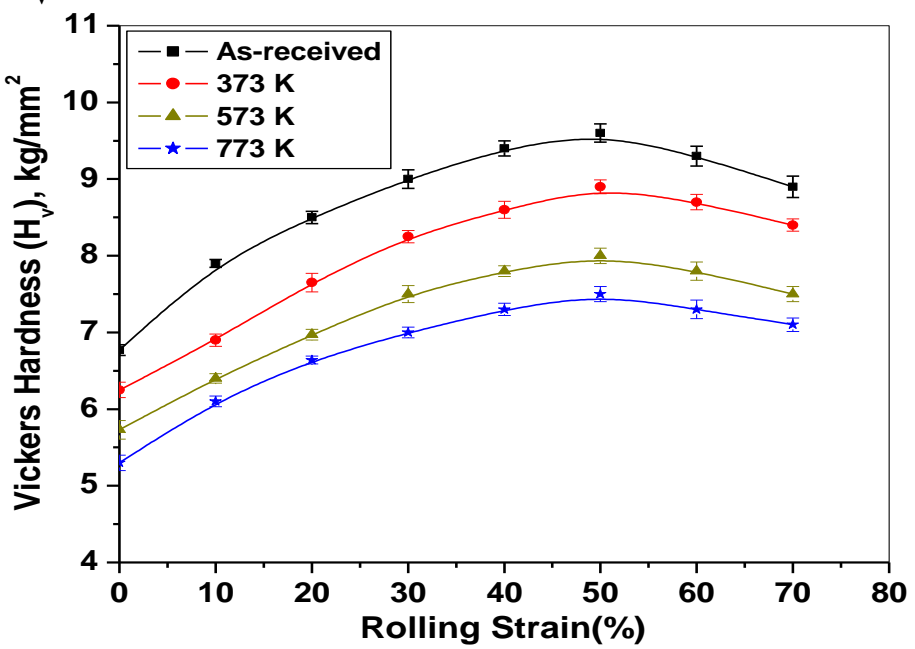

Fig. (3): Effect of rolling strains on hardness measurements of $\mathrm{Al}$ samples.

\subsection{Electrical Resistivity}

Figure (4) shows the dependence of electrical resistivity on the rolling strain of the as-received sample as well as a selected annealed one at $773 \mathrm{~K}$. It can be seen that the electrical resistivity continues to increase, passing through a maximum of $286 \mathrm{n} \Omega \mathrm{m}$ at rolling strain of $40 \%$ followed by a noticeable decrease as the rolling strain increases up to $70 \%$. This is nearly similar to the hardness behaviour shown in Fig. (3). The material with high hardness also shows high electrical resistivity, and vice versa.

Apparently, the microstructural features giving rise to the hardness increase during rolling are also responsible for the decrease in electron mobility manifested in the electrical resistivity. Furthermore, this increase in the electrical resistivity with increasing the rolling strain up to $40 \%$ may be attributed to the increase of the number of vacancies and the density of dislocations [21-23].

On the other hand, the noticeable decrease in the electrical resistivity as the rolling strain increases up to $70 \%$ was also reported by others [24] and attributed to the decreasing solute concentration in the matrix.

Also, Fig. (4) shows that the electrical resistivity decreases with annealing temperature due to recovery and recrystallization. After annealing, the electrical resistivity level is lower than that the as-received one. Two effects contribute to the decrease in electrical resistivity: (1) the annihilation of vacancies during the recovery and (2) the decrease of dislocation density during the recrystallization both decrease electrical resistivity. 


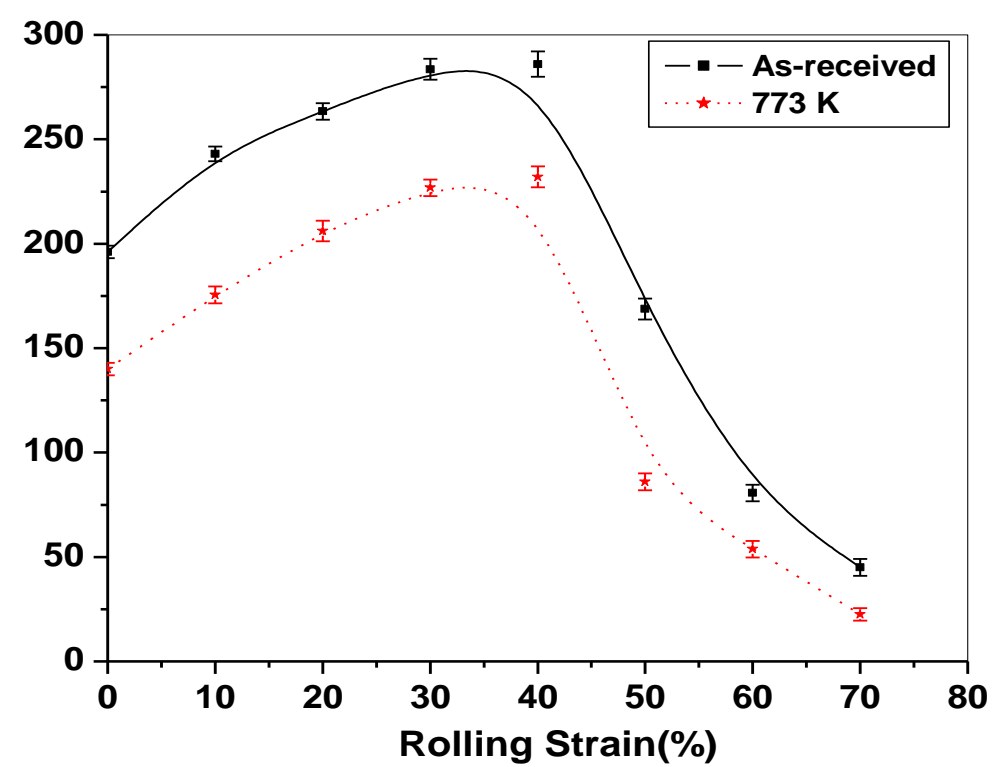

Fig. (4): Dependence of electrical resistivity of both as-received as well as annealed Al samples on rolling strain.

It should be noted that the peaks of both hardness and electrical resistivity given in Figs. ( $3 \& 4)$ should be more or less reached at the same rolling strain. This claim is based on the fact that the microstructural features responsible for the increase of both hardness and electrical resistivity are the same for any sample exposed to the same rolling strain.

However, this did not happen in the present work and the positions of the two peaks were slightly different. We believe the reason for this difference is that the measurements of the given electrical resistivity were recorded at the room temperature rather than at low temperature.

\subsection{X-ray Diffraction Analysis}

The XRD patterns of the above treated samples are given in Figs. (5 \& 6) and show the following remarks:

- The only crystalline planes detected were of Al phase.

- The elemental traces ( $\mathrm{Si}, \mathrm{Zn}, \mathrm{Fe}$ and $\mathrm{Ti}$ ) of this alloy were not detected by the XRD analysis.

- The rolling process changed the percentage of relative intensities of most crystalline planes as shown in Fig. (5). This shift in the percentage of relative intensities is believed due to the elongation effect of the sample caused by rolling process and shown previously in Fig. (2).

- The annealing process at different temperatures of samples rolled to a constant chosen strain (70\%) also changed the percentage of relative intensities of most crystalline planes as shown in Fig. (6). 


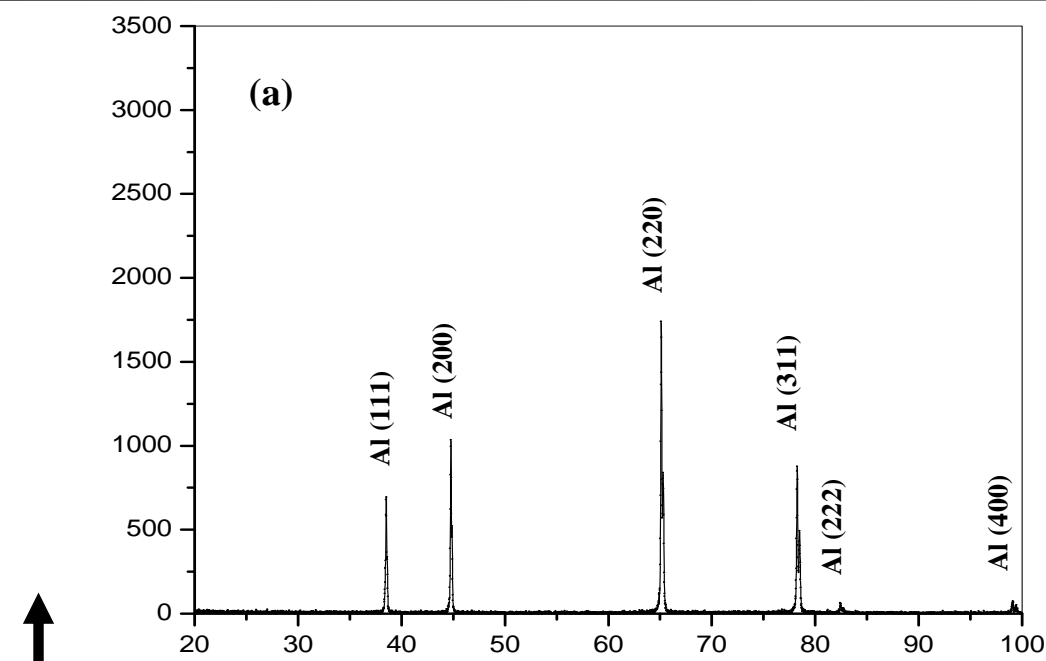

告
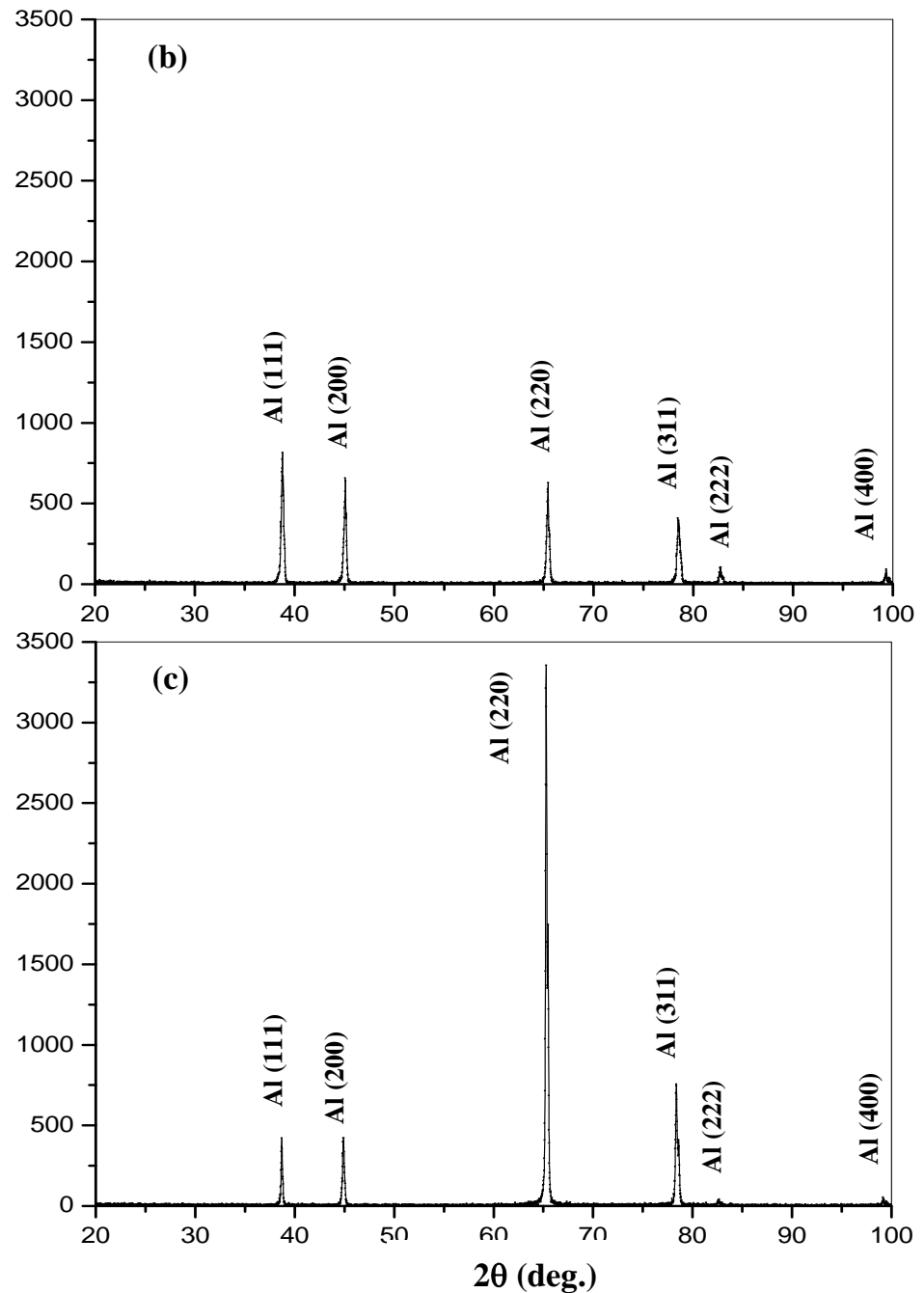

Fig. (5): X-ray diffraction patterns obtained tor commercial Al samples rolled to strains

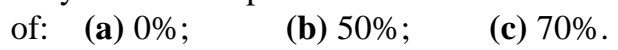




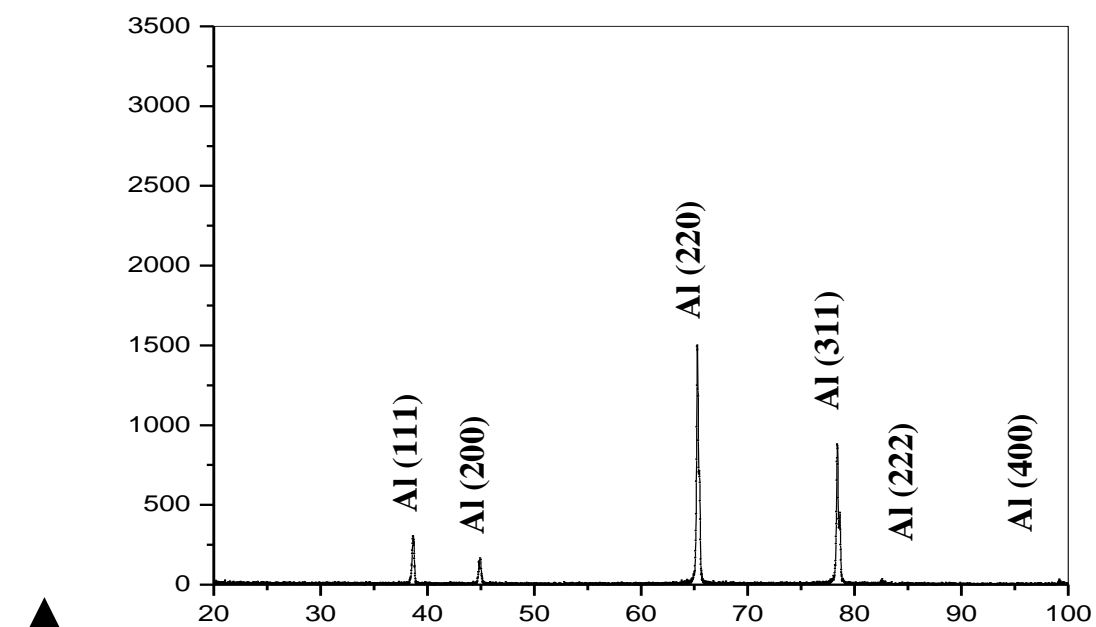

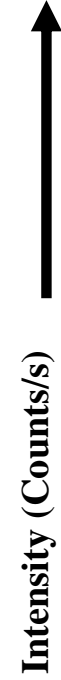
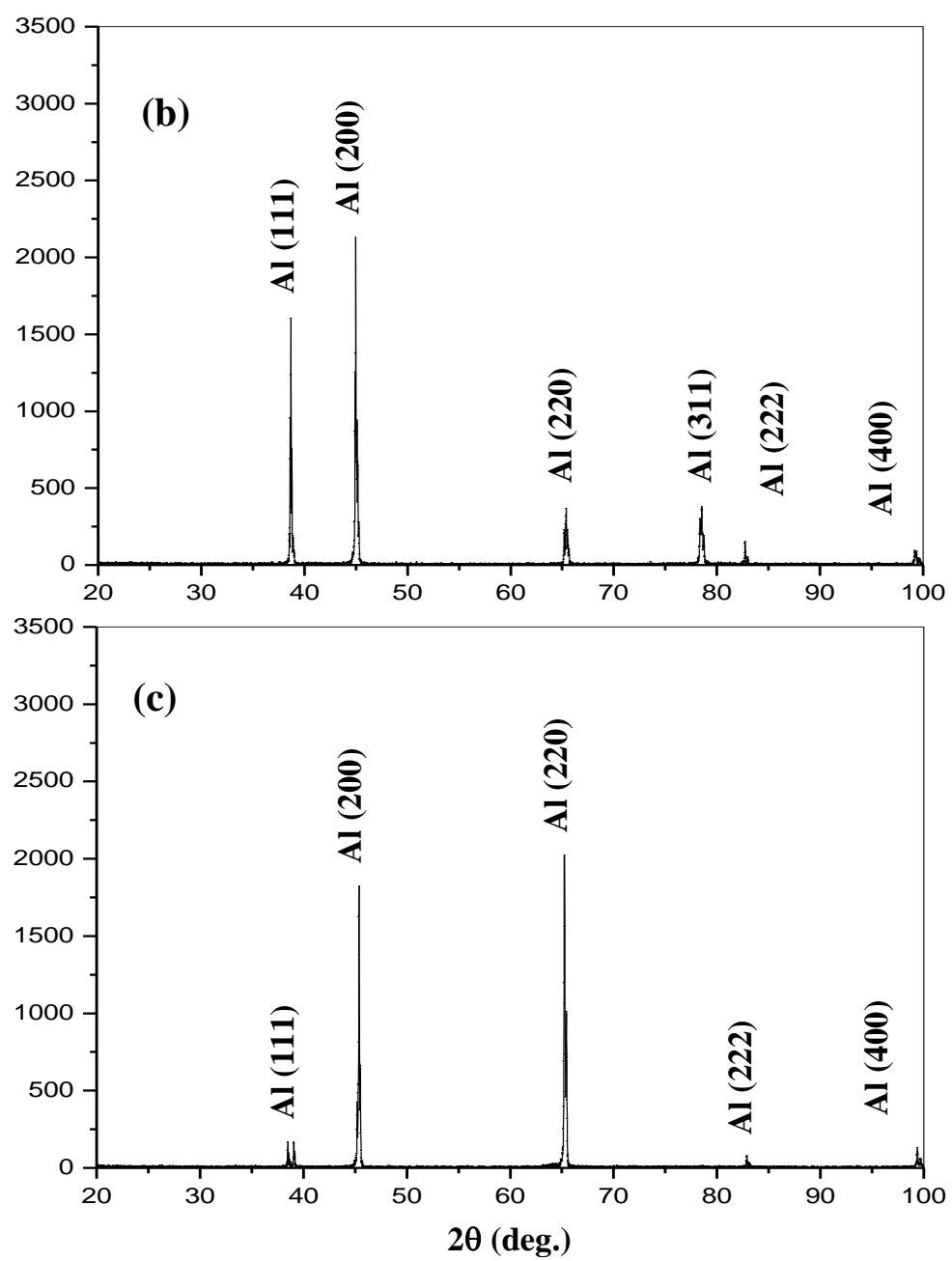

Fig. (6): X-ray diffraction patterns obtained for commercial Al samples rolled to a constant strain of $70 \%$ then annealed for $1 \mathrm{~h}$ at different temperatures: (a) 373 K; (b) $573 \mathrm{~K}$; (c) $773 \mathrm{~K}$. 
Furthermore, the particle sizes of Al planes were calculated from the half width of the spectral lines using Scherer's formula [25]. The change in the average particle size associated with increasing annealing temperature are given in Fig. (7). It was observed from this figure that the average particle size of $\mathrm{Al}$ was increased with increasing the annealing temperature.

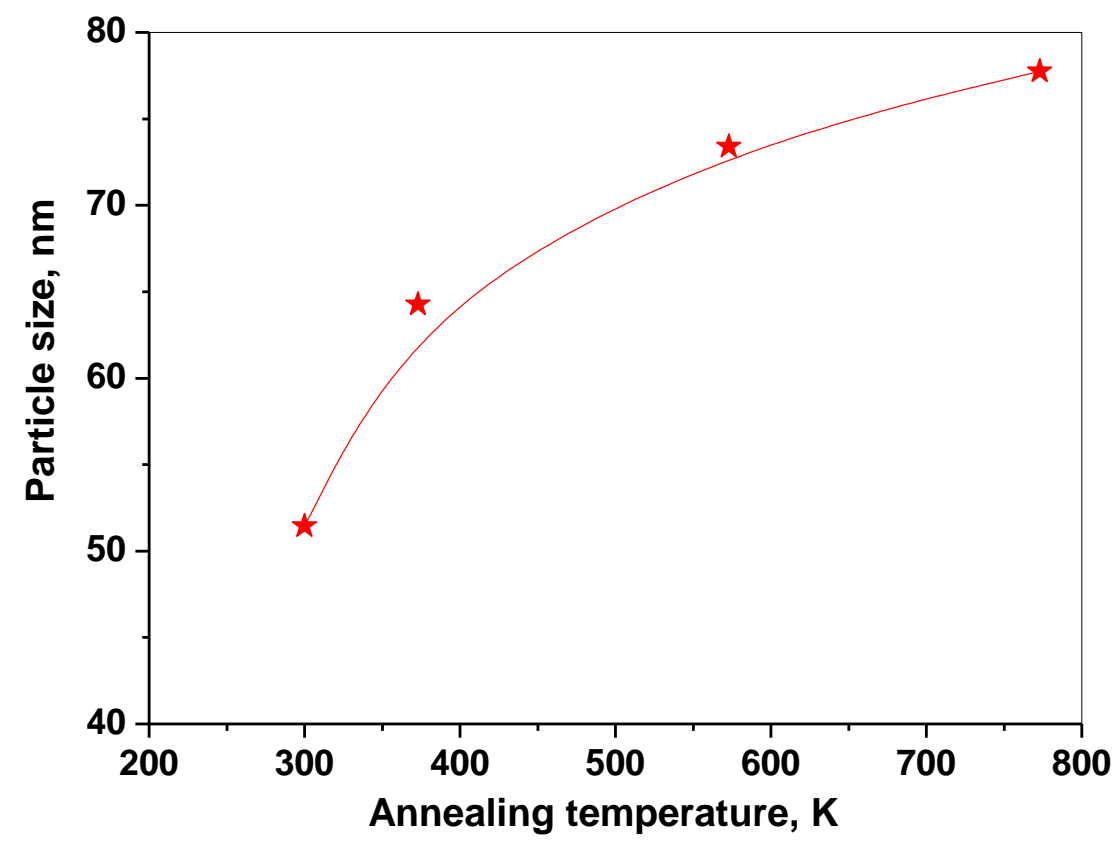

Fig. (7): Variation of average particle size of the Al phase with annealing temperature (after rolling to strain of $70 \%$ ).

\section{Conclusions:}

Effects of annealing temperatures on structural, mechanical and electrical properties of rolled commercial $\mathrm{Al}$ alloy were investigated. The main conclusions were drawn as follows:

- Cold rolling increased the Vickers hardness value; the larger the rolling strain, the higher is the Vickers hardness value.

- The maximum value of hardness $(9.6 \mathrm{HV})$ was attained at $50 \%$ rolling strain.

- Annealing the rolled samples weakened the material (less Hv values).

- The observed drop in hardness value of the different samples rolled to a strain above $50 \%$ is attributed to the recovery mechanism.

- The electrical resistivity of different Al samples increased with increasing rolling strain up to $40 \%$ then decreased sharply.

- Cold rolling as well as annealing temperature separately changed the percentage of relative intensities of most $\mathrm{Al}$ crystalline planes. 


\section{References:}

1. K. Mizuno, A. Nylund, I. Olefjord, Corrosion Science 43, 381(2001).

2. D.G. Altenpohl: Aluminum: Technology, Applications and environment. TMS and Aluminum Association (1998).

3. E. Tillová, M. Chalupová, L. Hurtalová, M. Bonek, L.A. Dobrzanski, Structural analysis of heat treated automotive cast alloy, Journal of Achievements in Materials and Manufacturing Engineering 47/1, 19 (2011).

4. P.K. Seo, D.U. Kim, C.G. Kang, Journal of Material Processing Technology 162, 570 (2005).

5. T. Haga, P. Kapranos, Journal of Material Processing Technology 130, 594 (2002).

6. S. Nafisi, R. Ghomashchi, Journal of Materials Characterization 57, 371 (2006).

7. M. Rosso, I. Peter, Journal of Achievements in Materials and Manufacturing Engineering 52/2, 59 (2012).

8. T. Haruna, T. Kouno, S. Fujimoto, Corros. Sci. 47, 2441 (2005).

9. E. Hur, G. Bereket, Y. Sahin, Curr. Appl Phys. 7, 597 (2007).

10. A.M. Addel-Gaber, B.A. Abd-El-Nabey, I.M. Sidahmed, A.M. El-Zayady, M. Saadawy, Mater. Chem. Phys. 98, 291 (2006).

11. Lj. Radović, M. Nikačević, Scientific Technical Review, LVIII (2), 14(2008).

12. D.H. Bae, A.K Ghosh, Acta Materialia, 48, 1207 (2000).

13. S.X. Girard, H.N. Azari and D.S. Wilinson: Metall. Mater.Trans. A, 35A, 949 (2004).

14. W. Wen, J.G. Morris,: Mat.Sci.Eng A 354, 279 (2003).

15. G. Petzow, Metallographic Etching, American Society for Metals, 59, 40 (1978).

16. F.J. Humphreys, in "Processing of metals and alloys", Ed. by R. W. Cahn, VCH, Germany 9, 373 (1991).

17. D. Chandrasekaran, Grain Size and Solid Solution Strengthening in Metals: A Theoretical and Experimental Study, Royal Institute of Technology, SE-100, 44 Stockholm, Sweden (2003).

18. M. Bader, G. T. Eldis, H. Warlimont, Met. Trans.7A, 249 (1976).

19. J.M. Vitek, H. Warlimont, Metall. Trans., 10A, 1889 (1979).

20. R.E. Smallman, Modern Physical Metallurgy (Butterworths, London) 318 (1970).

21. S. Nestorovic, D. Markovic, Lj. Ivanic, Bull.Mater.Sci., 26 (6), 601 (2003).

22. L.F. Mondolfo: Aluminium Alloys: Structure and Properties, Boston, Butterworths, (1976).

23. American Society for Metals, Metals Handbook, Metals Park, Ohio, 2 (1979).

24. K. Osamura, N. Otsuka and Y. Murakami, Philo. Mag. B, 45, 583 (1982).

25. B.D.Cullity, Elements of X-ray Diffractions, second edition, AddisonWesley Publishing Company, Inc. 284 (1978). 